九州大学学術情報リポジトリ

Kyushu University Institutional Repository

\title{
DESCRIPTIONS OF A NEW GENUS AND TWO NEW SPECIES OF PSELAPHINI (COLEOPTERA, PSELAPHIDAE) FROM JAPAN AND TAIWAN
}

Nomura, Shuhe i

https://doi.org/10.5109/2526

出版情報 : ESAKIA. Special Issue 1, pp.51-55, 1990-04-20. Entomological Laboratory, Faculty of Agriculture, Kyushu University

バージョン :

権利関係 : 


\title{
DESCRIPTIONS OF A NEW GENUS AND TWO NEW SPECIES OF PSELAPHINI (COLEOPTERA, PSELAPHIDAE) FROM JAPAN AND TAIWAN*
}

\author{
Shuhei NomuRA \\ Entomological Laboratory, Faculty of Agriculture, \\ Kyushu University, Fukuoka, 812 Japan
}

\begin{abstract}
A new genus Hirashimanymus of the tribe Pselaphini (Pselaphidae, Pselaphinae) and two new species H. schistodactyroides and H. babai are described and illustrated from southwest Japan and Taiwan.
\end{abstract}

This paper presents a new genus of the tribe Pselaphini and two new species from Ishigaki Is., southwest Japan and Taiwan. The name of the new genus is dedicated with gratitude to Prof. Emer. Yoshihiro Hirashima for his continuous encouragement and guidance.

Hirashimanymus gen. nov.

Type species : Hirashimanymus schistodactyroides sp. nov.

Body medium-sized, broadened posteriorly, coarsely punctate in dorsal surface.

Head weakly narrowed anteriorly, clypeogenal areas weakly laminate, frons broadly nodulate, vertex broad, with a pair of indistinct dorsal tentorial pits ; eyes ovoid, convex ; antennae elongate, very irregularly segmented in length, densely with coarse punctures, each segment subcylindrical ; maxillary palpi 3-segmented, 3rd segment largest, thick and rounded in basal part, tapered toward apex, with a short spine or denticle.

Pronotum round-sided, simple on dorsal surface ; elytra broadened posteriorly, humeri weakly expanded in male, almost flat in female, each elytron with 4 basal foveae; hind wing developed in male, reduced in female ; legs slender, femora densely with coarse punctures, tibiae slender, each with a few suberect hairs, tarsi large, 3rd segment largest, lobate and rounded in ventroapical part, with a large, scythe-shaped claw.

Abdomen shorter than elytra, 4th segment largest, with a transverse groove in basal part, 5th to 8th segments shortened successively.

The genus Hirashimanymus nov. is classified into the tribe Pselaphini by the single claw of the tarsus and the large terminal segment of the maxillary palpus. This genus is conspicuously characterized by the antenna which is irregularly segmented in length, the third segment of maxillary

* Contribution from the Entomological Laboratory, Faculty of Agriculture, Kyushu University, Fukuoka (Ser. 4, No. 6). 
palpus with the external spine or denticle, the third tarsal segment being lobate in the ventroapical part, and the large and scythe-shaped tarsal claw.

\section{Hirashimanymus schistodactgroides sp. nov. (Figs. 1, 2A-C, F, 3A-B, D-F)}

Male : Length $1.5 \mathrm{~mm}$. Width $0.6 \mathrm{~mm}$. Body reddish brown, legs light brown, narrowed anteriorly.

Head longer than wide, weakly narrowed anteriorly, coarsely punctate in dorsal surface, clypeus short, with a pair of lateral lobes continued to genal areas, frons narrow and weakly nodulate, with a short, shallow longitudinal sulcus in its anterior part, vertex very weakly convex, postgenae very short, eyes large and convex, each composed of about 25 facets. Antennae $0.95 \mathrm{~mm}$ long, slender, reaching the middle of elytra, densely with very coarse punctures, densely pubescent, each segment

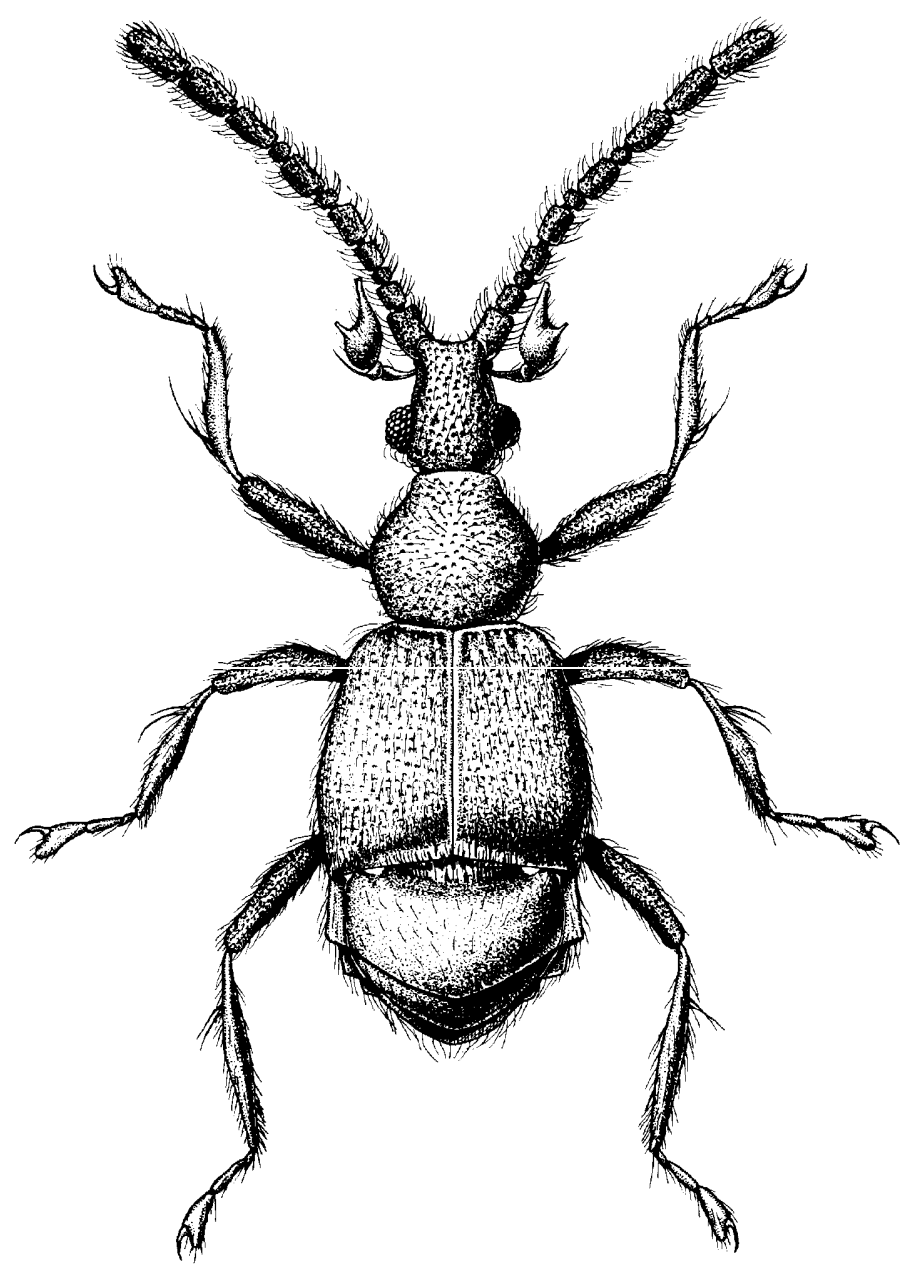

Fig. 1. Hirashimanymus schistodactyroides gen. et sp. nov., holotype, dorsal aspect. 
subcylindrical, terninal 3 segments each slightly thickened distally, relative lengths (widths) of segments from base to apex as $2.0(1.2): 1.0(1.0): 0.5(0.8): 1.0(1.0): 1.4(1.0): 0.6(0.8): 1.6(1.0): 0.6$ $(0.8): 1.8$ (1.1) : 1.8 (1.1) : 2.3 (1.2). Labrum very short, transverse ; mandibles short, each broad at base, acute at apex, with 5-7 small teeth ; maxillae small, maxillary palpi S-segmented, 1st segment elongate, narrowed and strongly curved near base, thickened distally, 2nd short and broad, with a long seta on external side, 3rd largest, transverse and thick in basal part, tapered apically, truncate at apex, with a short and truncate spine at external side ; labium about as long as maxilla, labial palpi 3-segmented, 1st short, 2nd elongate, curved laterally, 3rd piliform.

Pronotum slightly wider than long, rounded on both sides, weakly convex, coarsely punctate. Elytra wider than long, weakly broadened posteriorly, flattened in basal part, coarsely punctate on dorsal surface, densely pubescent on posterior margin, humeri slightly expanded, each elytron with 4 basal foveae and indistinct sulci ; hind wings developed. Legs elongate and slender, fore tibiae weakly swollen in basal $2 / 5$, each with a few suberect long hairs at basal $2 / 5$, mid and hind tibiae weakly swollen in the middle, each with a few suberect hairs in basal $1 / 3$, tarsi large, broadened distally, 1st segment short, 2nd elongate, thickened distally, 3rd very large, broadly extending ventrally forming an apical lobe, excavated in dorsoapical part, tarsal claw very long, scythe-shaped, attached to apex of the ventroapical lobe of 3rd segment, put up into the dorsoapical groove in basal part when it pulled up dorsally.

Abdomen slightly narrower than elytra, 4th segment largest, subparallel-sided, weakly convex, sparsely punctate, with a pair of thick and short basidorsal carinae hidden by elytra in basal $1 / 5$, and a broad, transverse groove covered with a lot of thick setae behind the basidorsal carinae, 5th to 7 th

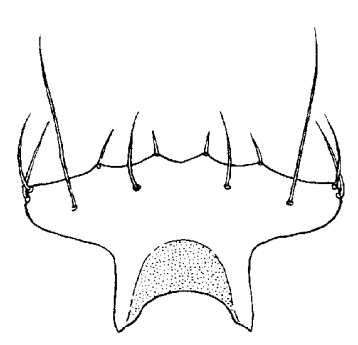

A
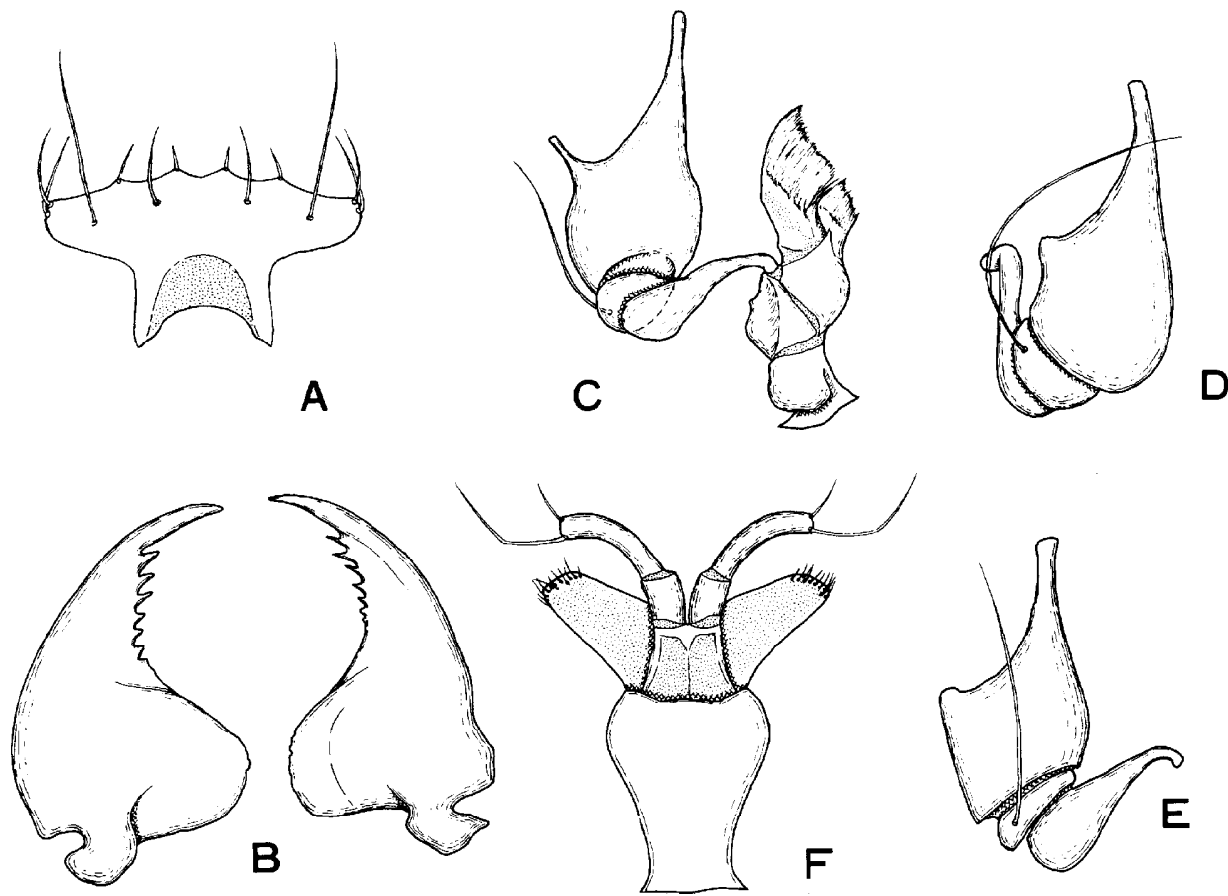

Fig. 2. A-C, F : Hirashimanymus schistodactyroides gen. et sp. nov., male. D-E : H. babai sp. nov., female. A : labrum dorsal view. B : mandibles dorsal view. C : maxilla, ventral view. D : maxillary palpus, ventral view. E : ditto, lateral view. F : labium ventral view. 
short, 8th tergite very small, nearly triangular, 8th stemite small, arcuately emarginate on posterior margin.

Female : Length $1.7 \mathrm{~mm}$. Width $0.6-0.7 \mathrm{~mm}$. Similar to male, but differs as follows: Eyes smaller than in male, each composed of about 20 facets ; antennae shorter than in male, $0.80 \mathrm{~mm}$ long, reaching base of elytra, relative lengths (widths) of segments from base to apex as $1.5(1.2): 1.1$ (1.0) : 0.5 (0.9): 0.6 (0.9) : 1.1 (1.0): 0.7 (0.9) : 1.1 (1.0) : 0.7 (0.9): 1.3 (1.0): 1.2 (1.1): 2.2 (1.3); elytra trapezoid, moderately convex ; hind wings reduced ; abdomen as wide as elytra.

HolotyPe ơ (Type No. 2773, Kyushu Univ.), Mt. Omotodake, Ishigaki Is., Okinawa Pref., 9. iv. 1986, S. Nomura leg.

Paratypes :19, Piluchi, Nantou Hsien, Central Taiwan, 18. vii. 1988, S. Nomura leg. ;19, Tayulin, Nantou Hsien, Central Taiwan, 28. v. 1989, K. Baba leg.

DisTRIBUTION : Japan (Ishigaki Is.) and Taiwan.

BIOLOGY : Type specimens were captured from the litter in the subtropical primary forest.

This new species has the large tarsi looking like bifurcate such as the genus Schistodactyms (Pselaphinae, Schistodactyrini) in Australia ; but each tarsus extended in ventroapical part in the third segment in Hirashimanymus, in the second segment in Schistodactyrus.

\section{Hirashimangmus babai sp. nov.} (Figs. 2D-E, 3C, G-I)

Male. Unknown.

Female. Length $1.5 \mathrm{~mm}$. Width $0.6 \mathrm{~mm}$.

Body reddish brown, legs and maxillary palpi light brown, broadened posteriorly.

Head longer than wide, narrowed anteriorly, densely with coarse punctures in dorsal surface, clypeus short, clypeogenal areas weakly laminate, frons narrow, weakly nodulate, with a shallow median longitudinal sulcus in anterior part, vertex flat, with a pair of very small dorsal tentorial pits, postgenae flat. Eyes ovoid and convex, each composed of 20 facets. Antennae $0.81 \mathrm{~mm}$ long, with coarse and dense punctures, densely pubescent, relative lengths (widths) of segments from base to apex as 1.6 (1.3): 1.1 (1.0): 0.5 (0.8): 0.6 (1.0): 1.0 (1.0): 0.7 (0.9) : 1.2 (1.0): 0.6 (0.8) : 1.1 (1.1): 1.2 $(1.1): 2.3$ (1.3). Maxillary palpi 3-segmented, 1st segment elongate, thickened distally, 2nd short and transverse, with a very long seta being arcuately curved dorsally, 3rd thick and rounded in basal part, tapering toward apex, with a short, obtuse denticle on ventral side.

Pronotum distinctly wider than long, rounded on both sides, weakly convex, densely with coarse punctures. Elytra wider than long, nearly trapezoid, weakly convex, coarsely punctate, humeri almost flat, each elytron with 4 basal foveae. Legs elongate, densely pubescent, femora thick, with very coarse and dense punctures, tibiae slender, weakly thickened near the middle, each with a few suberect hairs at basal $1 / 4$ to $1 / 3$, tarsi thick, 1 st segment short, 2nd longer than wide, weakly thickened distally, 3rd about twice as long as 2nd, weakly angulate in the middle of dorsal surface, claw longer than 2nd segment, scythe-shaped, attached to the apex of 3rd segment.

Abdomen rounded posteriorly, slightly narrower than elytra, densely pubescent, 4th segment largest, weakly broadened posteriorly, with a transverse groove in basal part, 5th to 7th successively shortened and narrowed posteriorly, 8th tergite very short, nearly triangular in posterior view, 8th stemite short, transverse, arcuately emarginate on posterior margin.

HoLotype $q$ (Type No. 2774, Kyushu Univ.), Mt. Taton-Shan, Taipei Hsien, Northern Taiwan, 17. iii. 1989, K. Baba leg.

Distribution : Taiwan.

This is closely allied to H. schistodactyroides sp. nov., but is separated by the third segment of the 


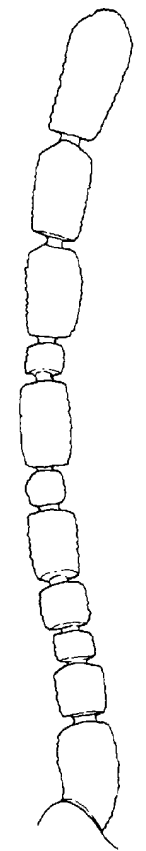

A

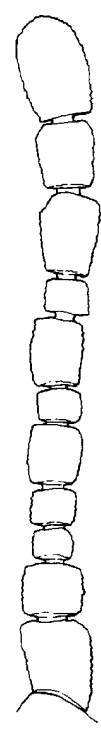

B

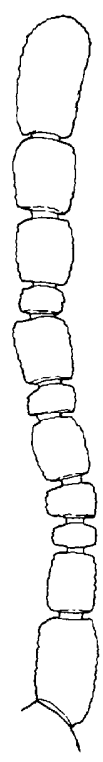

C
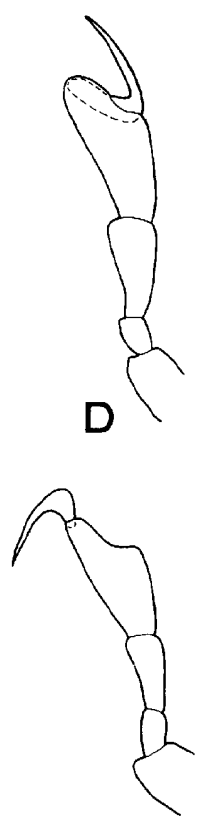

G
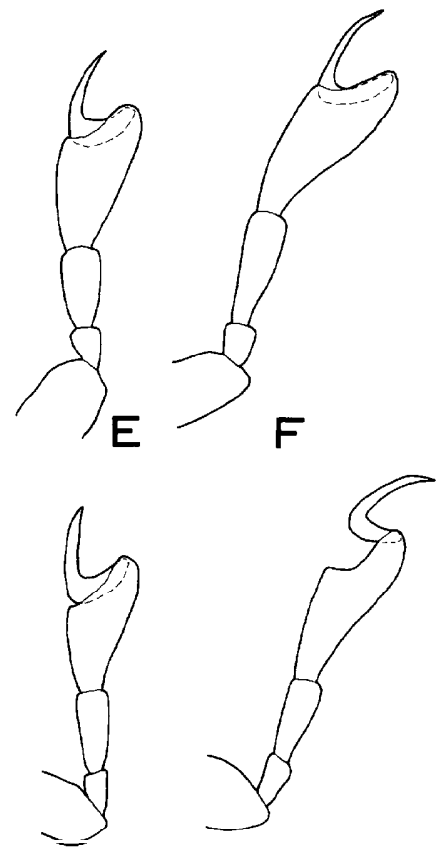

$\mathrm{H}$
I

Fig. 3. A : Hiyashimanymus schistodactyroides gen. et sp. nov., male. B, D-F : ditto, female. C, G-I : H. babai sp. nov., female. A-C: right antenna. D, G : fore tarsus. E, H : mid tarsus. F, I : hind tarsus.

maxillary palpus with a very short and obtuse denticle on external side and the pronotum which is distinctly wider than long.

\section{Acknowledgements}

I wish to express my sincere thanks to Prof. Emer. Y. Hirashima for his constant guidance and encouledgement. I am also much indebted to Prof. K. Morimoto, Entomological Laboratory, Kyushu University for his continuous guidance and review of the manuscript. I extend special thanks to Dr. D. S. Chandler, University of New Hampshire for giving me helpful suggestion and an oppotunity to examine some valuable materials. My cordial thanks are also due to Dr. K. Baba, Niigata Prefecture for his kindness in offering me valuable specimens.

\section{References}

Jeannel, R., 1959. Revision des Psélaphides de l'Afrique intertropicale. Ann. Mus.roy. Congo

Beyge, Sér. 8, (Zool.), 75 : 1-742.

Newton, Jr., A. F. and D. S. Chandler, 1989. World catalog of the genera of Pselaphidae (Coleoptera).

Field. Zool., (53) : 1-93.

Raff ray, A., 1904. Genera et catalogue des Pselaphides. Ann. Soc.ent. Fy., 73 : I-476, 635-658. 